\title{
A few words about evolution
}

\section{Building a hierarchical framework on the foundations of darwinism.}

\author{
The Structure of Evolutionary \\ Theory \\ by Stephen Jay Gould \\ Belknap: 2002. 1,464 pp. \$39.95, £27.50, \\ 45.90 euros
}

\section{David B. Wake}

We live in a darwinian world. For many evolutionary biologists the ever-extending grand evolutionary synthesis promulgated in the 1930s and 1940s offers adequate explanations and serves as a consistent generator of testable hypotheses. For Stephen Jay Gould it is but a foundation, wholly inadequate to be a framework within which to build. Evolution proceeds in a hierarchical manner, so proper analysis requires a hierarchical approach, Gould believes.

Modern darwinians, being largely reductionist in approach — while paying some lip-service to the possibility of constraints, the reality of mass extinctions and the like view evolution in general as microevolution plus lots of time and some contingency. Gould strongly rejects this perspective. His views are well known, but they have had surprisingly little effect on some of the core disciplines in evolutionary biology, such as population, and quantitative and evolutionary genetics, whose practitioners see themselves as defenders and extenders of the darwinian message. In The Structure of Evolutionary Theory Gould makes a direct, intellectually rigorous argument that a hierarchical perspective would not only enrich modern darwinism, but that it is essential. This book is a manifesto for a new kind of evolutionary biology, one that makes full use of many kinds of knowledge as well as diverse 'ways of seeing'.

This large book demands attentive reading. Gould uses many more words than most writers and the book appears not to have been edited at all. Those who enjoy Gould's erudition and style will find this to be a stimulating and illuminating book; it will infuriate others. There are intellectual wars in progress in the evolutionary-biology community, but most researchers seem to care little about battles engaged around issues such as hierarchical versus reductionist approaches, and structuralist versus functionalist versus historical perspectives. I believe that these are important issues, and that in the long run evolutionary biology will have to confront them. Gould's book, an intellectual tour de force and a work of serious scholarship, will be a permanent factor in the struggle to understand how life has evolved.

Gould knows the book is long and daunt-
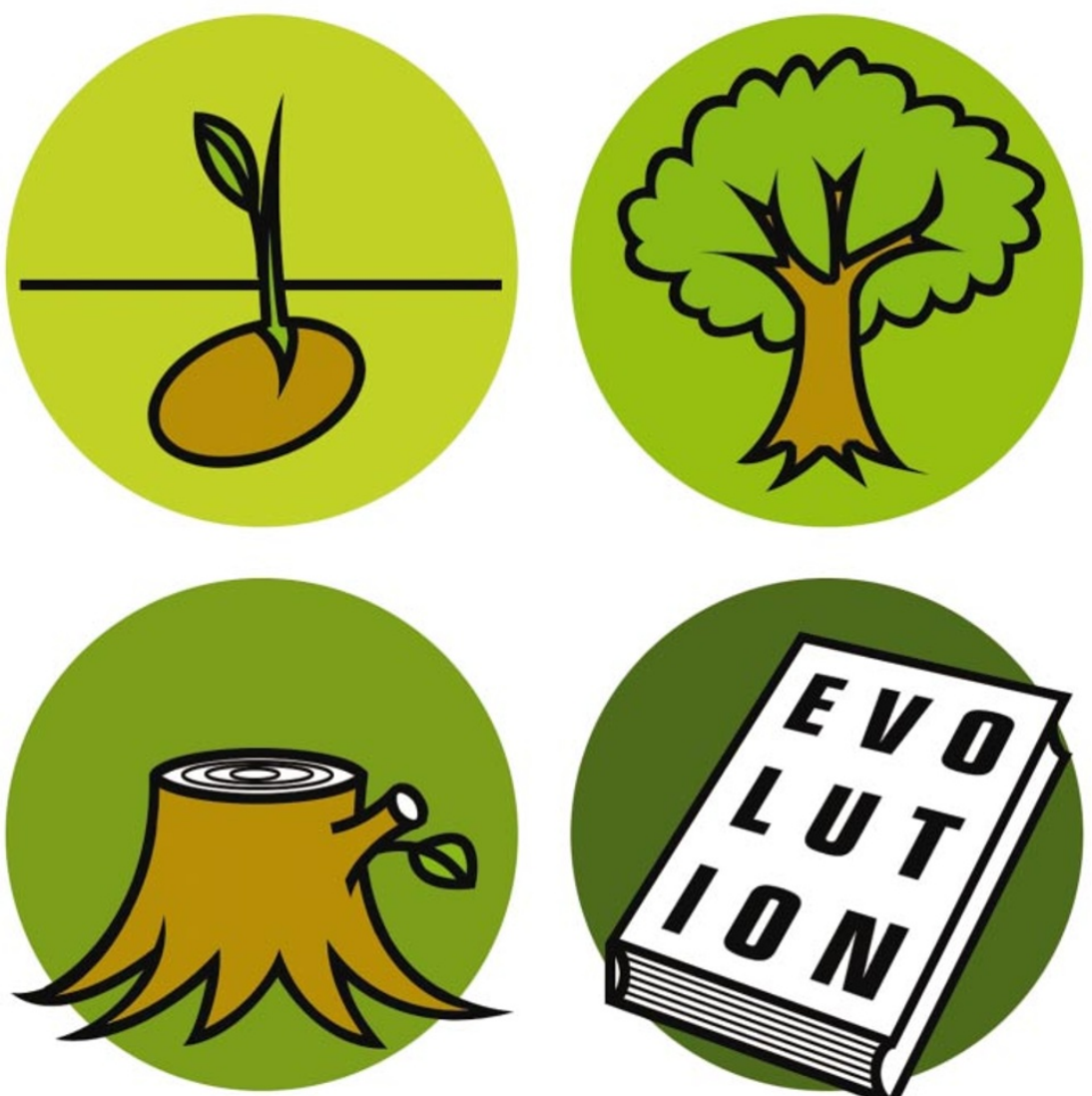

ing and has supplied readers with a kind of abstract, itself 89 pages long. In this opening chapter he previews, but cannot really encapsulate, the many deeply analytical historical and philosophical treatments to come. This is a long and circuitous argument that new knowledge and new macroevolutionary explanations have been so substantial that a full exposition of evolutionary theory within the domain of darwinian logic "must be construed as basically different from the canonical theory of natural selection, rather than simply extended". This point is made repeatedly throughout the book, lest anyone miss it.

The strategy is to examine the historical roots of evolutionary theory in great detail and to show how earlier workers, even Darwin (but excluding Wallace, who remained the ultimate pan-selectionist), were forced to resort to hierarchical thinking at some point in their intellectual journeys. The book is a veritable history of evolutionary biology, but not all of it, of course. Gould sets the agenda and discusses what he wishes from his point of view: that of a strong advocate for an expanded and greatly modified evolutionary theory.

All Gould's familiar arguments are here, with emphasis on levels of selection, punctu-

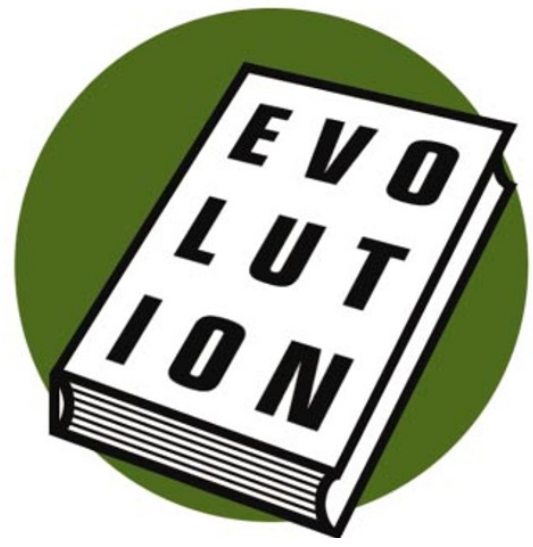

ated equilibrium, and their contribution to the development of Gould's hierarchical perspective. His points are forcefully made, but the arguments of only some of his detractors are considered. Gould makes a convincing case for the "hardening" of the adaptationist perspective during, and especially at the end of, the grand evolutionary synthesis in the middle of the twentieth century. He charges that evolutionists became almost blindly channelled. Selectionists will complain that their position is oversimplified.

In a time when we are in something of an intellectual revolution in our understanding of species and species formation, Gould is unrelentingly stubborn in his insistence that speciation is a big deal, that species are individuals, and that species selection is the critical keystone of a hierarchical approach. Close study of species formation has made me question the reality of species as bounded entities, and I am wary of the perspective that species are individuals. I find clade selection an attractive and more general alternative to species selection, but Gould will not give ground. Many of us are attracted to aspects of punctuated equilibrium, and the concept has stimulated much research over the past 30 years. But the insistence that it is a theory of the deployment of species over time and 
space makes many uneasy and leads to doubts that it is the core concept for the new hierarchical theory of evolution.

I thoroughly enjoyed many parts of the book, for example the long and rewarding chapter on the evolution of development with its strong focus on the positive evolutionary effects of constraints, and the concluding chapter that deals extensively with spandrels. The structuralist message of these chapters is strong and clear, but it is integrated with functionalist and historical perspectives as well. Parallel evolution is given the attention I believe it merits, and Gould does an admirable job of showing why it is important. A fan of Hox genes (he loves the word 'hoxology'), Gould also shows the importance of developmental genetics for his hierarchical perspective and for understanding the evolution of form in organisms.

Gould, the most widely known evolutionist of our time, has remained active in research while at the same time communicating his evolutionary message to the public through his prolific writings and appearances. This book demonstrates that he is not just a popularizer, but a major intellectual force in his discipline. Yet one can predict a strong negative reaction because the book is annoyingly self-congratulatory and selfserving. But what can he do? He is certain that he is right! A strength, and at the same time a weakness, of this book is that the author's powerful personality emerges on nearly every page. The important messages of this book are appreciated most fully when the reader accepts and enjoys the idiosyncrasies of this extraordinary man.

David B. Wake is at the Museum of Vertebrate Zoology, University of California, Berkeley, California 94720-3160, USA.

\section{The nature of nature's economy}

\section{Human Well-Being and the Natural Environment \\ by Partha Dasgupta \\ Oxford University Press: 2001. $£ 25$ \\ The New Economy of Nature: The Quest to Make Conservation Profitable \\ by Gretchen Daily \& Katherine Ellison Island Press: 2002. $£ 19.50$}

\section{Norman Myers}

We overexploit our environments and we underutilize them. We convert forests into newspapers with disregard for their many other outputs such as watershed functions and climate regulation. We drain wetlands for housing to the detriment of their role in flood control and as species habitats. Yet it is the abundant 'ecosystem services' that often

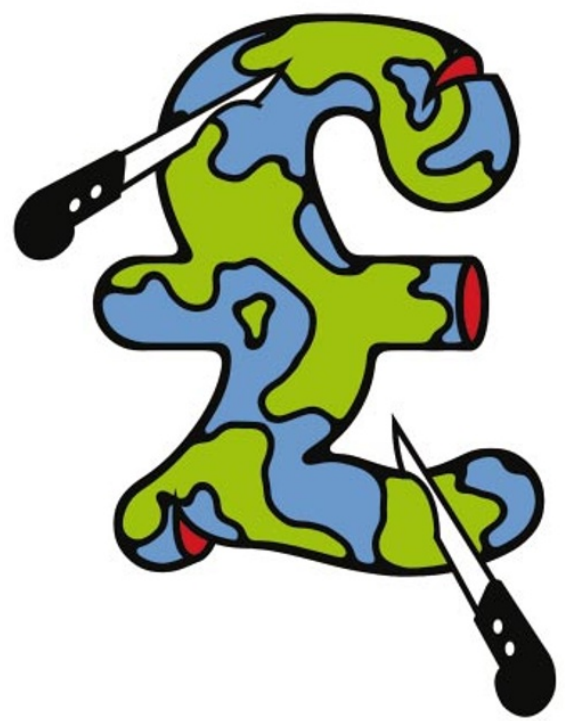

offer more to society than limited products with limited benefits. But everybody's benefits tend to be nobody's business as nobody owns the ecosystems services, so nobody has an incentive to protect them. Everybody's atmosphere becomes everybody's garbage bin for pollutants, and everybody's river becomes everybody's sewer.

Let us welcome, then, these two books, which show us how to get on top of the problem before it gets on top of us. Human Well-Being and the Natural Environment, by a past president of the British and European Economics Associations, focuses on the contributions of ecosystem services to the quality of life, with emphasis on impoverished communities of developing countries. The author is concerned that even though the natural environment is central to our lives, it is "absent from national accounts, from quality-of-life indices, and, more generally, from official development economics". Hence, we "must stop viewing the environment as an amenity, a luxury the poor can't afford". In fact, Dasgupta argues that the environment is often the greatest asset for poor families because they have few alternatives for income if it fails.

The book ranges over such disparate topics as well-being (both personal and social), GNP as a measure of well-being (deeply inaccurate and even misleading as it is), the Human Development Index (the United Nations' measure of social and economic advancement), poverty and consumption, population pressures, technological change, markets and other economic institutions, common property resources, economic efficiency versus social equity, intergenerational conflicts, human rights and civil rights. All are accorded a firm theoretical treatment. The book is solidly interdisciplinary, covering not only economics but ecology, anthropology, political science, philosophy and ethics. It should make a first-rate reader for the World Summit on
Sustainable Development in Johannesburg next August.

While it gives a comprehensive account of what makes up human well-being, the book frequently diverges from certain conventional views. "Countries that would be regarded as having performed well if judged on the basis of such indices as GNP per head or the Human Development Index are found to have grown poorer... the poorest countries have 'developed' by depleting natural capital relative to their high population growth rates." Indeed, Dasgupta deeply disagrees with those many economists who assert that high population growth in poor countries has not slowed their development. Rather, he sees the problem lying with an interactive mix of "high fertility, poverty, malnutrition, illiteracy, and degradation of local natural resource bases, all of which feed on one another cumulatively". Decline of ecosystem services can often serve as a crucial catalyser of deficiencies in other sectors. In other ways, too, the book's message contrasts sharply with much contemporary thinking on economic development.

Parts of the book will prove too dense and technical for those with expertise outside economics. But Dasgupta outlines his theme in an introductory summary, a sort of roadmap for the many analytic pathways ahead. Each of the book's five parts is preceded by a prologue, further enabling the lay reader to grasp the guts of the discussion in short order. Moreover, Dasgupta frequently engages in happy phraseology that leavens the otherwise heavy text. For instance: "The present is the past's future, [and] the future has an unnerving habit of becoming the present." These stylistic flourishes help to make the book more accessible, which is all the more pertinent in that it addresses factors central to the human condition writ large. Indeed, Dasgupta is at pains to talk in terms more general than economicsspeak, and algebra is confined to a set of appendices. For the specialist, there are over 500 references.

The New Economy of Nature demonstrates that ecosystem services, although nobody's business in established practice, can become profitable business for "green gold prospectors". A good number of innovative entrepreneurs, both private and public, are making big money from these services. One well-known example is New York City, which depends for its water on a watershed, the Catskill Mountains, 125 miles away. The water supply could be maintained either through a water-filtration plant costing $\$ 6-8$ billion, plus annual maintenance expenses of \$300-500 million, or through an investment of $\$ 1.5$ billion to restore the watershed. No fewer than 140 American municipalities are now calculating the costs of protecting watersheds compared with the costs of building water-purification 